\title{
Sugar-fermenting yeast as an organic source of carbon dioxide to attract the malaria mosquito Anopheles gambiae s.s.
}

\author{
Renate C Smallegange ${ }^{1 *}$, Wolfgang H Schmied ${ }^{1}$, Karel J van Roey ${ }^{1}$, Niels O Verhulst ${ }^{1}$, Jeroen Spitzen ${ }^{1}$, \\ Wolfgang R Mukabana ${ }^{2,3}$, Willem Takken ${ }^{1}$
}

From Parasite to Prevention: Advances in the understanding of malaria

Edinburgh, UK. 20-22 October 2010

\section{Background}

Carbon dioxide $\left(\mathrm{CO}_{2}\right)$ plays an important role in the host-seeking process of opportunistic, zoophilic and anthropophilic mosquito species and is therefore commonly added to mosquito sampling tools. The African malaria vector Anopheles gambiae Giles sensu stricto is attracted to human volatiles augmented by $\mathrm{CO}_{2}$. We investigated whether $\mathrm{CO}_{2}$, usually supplied from gas cylinders acquired from commercial industry, could be replaced by $\mathrm{CO}_{2}$ derived from fermenting yeast (yeastproduced $\mathrm{CO}_{2}$ ).

\section{Methods}

Trapping experiments were conducted in the laboratory, semi-field and field, with An. gambiae s.s. as the target species. MM-X traps were baited with volatiles produced by yeast-sugar solutions, prepared in bottles. Catches were compared with traps baited with industrial $\mathrm{CO}_{2}$. The additional effect of human odours was also examined.

\section{Results}

Traps baited with yeast-produced $\mathrm{CO}_{2}$ caught significantly more mosquitoes than unbaited traps and also significantly more than traps baited with industrial $\mathrm{CO}_{2}$, both in the laboratory and semi-field. Adding yeast-produced $\mathrm{CO}_{2}$ to traps baited with human odour significantly increased trap catches. During the field trials, traps baited with yeast-produced $\mathrm{CO}_{2}$ caught similar numbers of An. arabiensis Patton as traps baited with industrial $\mathrm{CO}_{2}$. Addition of human odour increased trap catches.

\section{Conclusions}

We conclude that yeast-produced $\mathrm{CO}_{2}$ can effectively replace industrial $\mathrm{CO}_{2}$ for sampling of An. gambiae s.s. This will significantly reduce costs and allow sustainable mass application of odour-baited devices for mosquito sampling in remote areas.

\section{Acknowledgements \\ This study was funded by a grant from the Foundation for the National Institutes of Health (NIH) through the Grand Challenges in Global Health} Initiative (GCGH\#121).

\section{Author details}

'Laboratory of Entomology, Wageningen University, P.O. Box 8031, 6700 EH, Wageningen, The Netherlands. ${ }^{2}$ International Centre of Insect Physiology and Ecology, P.O.Box 30772 - 00100, GPO, Nairobi, Kenya. ${ }^{3}$ School of Biological Sciences, University of Nairobi, P.O. Box 30197 - 00100 GPO, Nairobi, Kenya.

Published: 20 October 2010

Cite this article as: Smallegange et al: Sugar-fermenting yeast as an organic source of carbon dioxide to attract the malaria mosquito Anopheles gambiae s.s. Malaria Journal 2010 9(Suppl 2):O29. 